\title{
Cytokine Gene Polymorphisms and Length of Gestation
}

\author{
Margaret Harper, MD, MSc, S. Lilly Zheng, MD, Elizabeth Thom, PhD, Mark A. Klebanoff, \\ MD, MPH, John Thorp Jr, MD, Yoram Sorokin, MD, Michael W. Varner, MD, Jay D. lams, \\ MD, Mara Dinsmoor, MD, MPH, Brian M. Mercer, MD, Dwight J. Rouse, MD, Susan M. \\ Ramin, MD, Garland D. Anderson, MD, and for the Eunice Kennedy Shriver National \\ Institute of Child Health and Human Development (NICHD) Maternal-Fetal Medicine Units \\ Network (MFMU) \\ Department of Obstetrics and Gynecology and the Center for Human Genomics at Wake Forest \\ University Health Sciences, Winston-Salem, North Carolina; the Department of Obstetrics and \\ Gynecology, University of North Carolina at Chapel Hill, Chapel Hill, North Carolina; Wayne State \\ University, Detroit, Michigan; the University of Utah Health Sciences Center, Salt Lake City, Utah; \\ The Ohio State University, Columbus, Ohio; Northwestern University, Chicago, Illinois; Case \\ Western Reserve University-MetroHealth Medical Center, Cleveland, Ohio; the University of \\ Alabama at Birmingham, Birmingham, Alabama; the University of Texas Health Science Center at \\ Houston, Houston, Texas; the University of Texas Medical Branch, Galveston, Texas; The \\ George Washington University Biostatistics Center, Washington DC; the Eunice Kennedy Shriver \\ National Institute of Child Health and Human Development, Bethesda, Maryland.
}

\begin{abstract}
OBJECTIVE-To estimate whether there is an association between length of gestation and gene polymorphisms that effect transcription of tumor necrosis factor- $\alpha$ (TNF- $\alpha$ ), interleukin-6 (IL-6), or interleukin-1 $\beta$ (IL-1 $\beta$ ).
\end{abstract}

\begin{abstract}
METHODS-Blood for DNA analysis was collected from 834 women at high risk enrolled in a randomized, clinical trial of omega-3 fatty acid supplementation for the prevention of recurrent preterm birth. Genotyping was performed for three single nucleotide polymorphisms (SNPs), TNF- $\alpha-308$, IL- $6-174$, and IL-1 $\beta+3954$. Women with the homozygous minor genotype were compared with women with either the heterozygous or the homozygous major genotype. KaplanMeier curves of gestational age at delivery and odds ratios for extreme preterm delivery were adjusted for African-American race and treatment group.
\end{abstract}

RESULTS-Women who were homozygous for the minor allele at the -308 position in the promoter region of the TNF-a gene had significantly shorter length of gestation than women who were either heterozygous or homozygous for the major allele (adjusted hazard ratio 1.74, 95\% confidence interval [CI] 1.04-2.90, $P=.03)$. Among women with this genotype, 20\% (3/15) experienced extreme spontaneous preterm delivery (less than 28 weeks of gestation; adjusted odds ratio $7.51,95 \%$ CI 1.84-30.72, $P=.005$ ). There was no difference in length of gestation or risk of extreme spontaneous preterm delivery by genotype for the IL- $6-174$ or the IL-1 $\beta+3954$ SNP.

\footnotetext{
(C) 2010 by The American College of Obstetricians and Gynecologists. Published by Lippincott Williams \& Wilkins. Corresponding author: Margaret Harper, MD, MSc, Mountain Area Health Education Center, 900 Hendersonville Road Suite 206, Asheville, NC 28803; harper.margaret@gmail.com.

*For a list of other members of the NICHD MFMU, see the Appendix online at http://links.lww.com/AOG/A213.

Presented at the $29^{\text {th }}$ Annual Meeting of the Society for Maternal Fetal Medicine, January 26-31, 2009, San Diego, California.

Financial Disclosure:

The authors did not disclose any potential conflicts of interest.
} 
CONCLUSION-Polymorphism at the -308 position in the TNF-a promoter region is associated with shorter gestation and an increased risk of spontaneous extreme preterm delivery.

Preterm birth is a major cause of neonatal mortality, morbidity, and long-term disability. ${ }^{1}$ Preterm parturition is a complex condition of etiologic heterogeneity but appears to be stimulated by a local inflammatory cytokine response in a significant proportion of preterm births, particularly extreme preterm births. ${ }^{2,3}$ Two proinflammatory cytokines, tumor necrosis factor- $\alpha(\mathrm{TNF}-\alpha)$ and interleukin- $1 \beta(\mathrm{IL}-1 \beta)$, not only mediate the inflammatory response but also induce changes in key components in the pathways of labor initiation and maintenance, including cervical ripening, rupture of the fetal membranes, and uterine contractions. These cytokines induce the production of uterotonic prostaglandins, matrix metalloproteinases, and oxytocin receptors. ${ }^{4-8}$ Interleukin-6 (IL-6) has been assigned both proinflammatory and antiinflammatory characteristics and plays a role in the transition from innate to acquired immunity. In the context of preterm delivery, IL- 6 is generally considered a proinflammatory cytokine and elevated fetal plasma levels are considered to be the marker for the fetal inflammatory response syndrome. ${ }^{9}$ Higher levels in maternal and fetal tissues or fluids have been associated with increased rates of preterm delivery. ${ }^{10-14}$ It is hypothesized that polymorphisms that modify gene transcription of these cytokines may alter the inflammatory response in pregnancy and predispose to an increased risk of preterm delivery. The concept that shortened gestation may be a heritable trait is supported by the fact that one of the strongest risk factors for delivering preterm is a personal or family history of preterm delivery. ${ }^{15-18}$

Previous studies have suggested an association between polymorphisms at the -308 position of the TNF- $\alpha$ gene, the -174 position of the IL- 6 gene, and the +3954 position of the IL- $1 \beta$ gene, and histologic chorioamnionitis, premature rupture of the fetal membranes, or fetal inflammatory disease. ${ }^{19-24}$ The TNF-a-308 minor polymorphism is a substitution of adenine (A) for guanine $(\mathrm{G})(\mathrm{G}>\mathrm{A})$. The IL-6 -174 minor polymorphism is a substitution of cytosine (C) for guanine $(\mathrm{G})(\mathrm{G}>\mathrm{C})$. The IL-1 $\beta+3954$ minor polymorphism is a substitution of thymine $(\mathrm{T})$ for cytosine $(\mathrm{C})(\mathrm{C}>\mathrm{T})$. The objective of this analysis was to estimate to what degree, if any, differences in these single nucleotide polymorphisms (SNPs) affect length of gestation or risk of extreme preterm delivery.

\section{MATERIALS AND METHODS}

The cohort consisted of women from 13 Eunice Kennedy Shriver National Institute of Child Health and Human Development Maternal Fetal Medicine Units Network centers enrolled in a randomized trial of omega- 3 fatty acid supplementation for the prevention of recurrent preterm birth between January 2005 and October 2006. The methods and results of the trial have previously been published. ${ }^{25}$ Inclusion criteria were a documented history of at least one previous singleton preterm delivery between 20 weeks and 0 days and 36 weeks and 6 days of gestation after spontaneous preterm labor or preterm premature rupture of the membranes and a current singleton pregnancy. Gestational age was determined according to a previously described algorithm on the basis of the last menstrual period and earliest ultrasound examination. ${ }^{26}$ Women were excluded if delivery before 37 weeks of gestation was planned. The study was approved by the Institutional Review Board of each clinical site and of the data coordinating center. Women gave written informed consent for study participation and had the options of agreeing to or refusing blood collection for DNA analysis. Trial participants received weekly injections of 17-a-hydroxyprogesterone caproate $(250 \mathrm{mg})$ and were randomized to receive either a daily supplement of 2,000 $\mathrm{mg}$ of omega-3 long-chain polyunsaturated fatty acids or matching placebo capsules. There were no differences in the rates of preterm delivery between the omega- 3 and placebo groups. 
Whole blood was collected from study participants before pregnancy loss or delivery and shipped to a central laboratory, the Center for Human Genomics at Wake Forest University Health Sciences, Winston-Salem, North Carolina. DNA was extracted from leukocytes using Autopure LS and then stored at $-20^{\circ} \mathrm{C}$ for later genotyping. Polymerase chain reaction and extension primers for the three SNPs were designed using MassARRAY Assay Designer 3.1. Information about the primers is available online at www.wfubmc.edu/genomics. Polymerase chain reaction assays were performed in a total volume of 5 microliters that contained $10 \mathrm{ng}$ of genomic DNA. Genotyping procedures followed the iPLEX Application Guide (Sequenom). Briefly, after polymerase chain reaction heat cycling, the mixture was incubated with shrimp alkaline phosphatase at $37^{\circ} \mathrm{C}$ for 40 minutes. iPLEX extension reactions were performed. Samples were desalted and dispensed to Spectro-CHIP. Chips were scanned and the genotypes were analyzed by MassARRAY type 3.4. Two Centre d'Etude Polymorphism Humain DNA and two water wells were run on each assay plate for quality control.

Pearson $X^{2}$ test was used to test for Hardy-Weinberg equilibrium for all three SNPs. Women with homozygous genotype for the minor allele were compared with women with either the heterozygous or the homozygous genotype for the major allele. Kaplan-Meier survival curves of gestational age at delivery, censored at 40 weeks of gestation, were generated and compared using the log-rank test for homogeneity. Cox proportional hazard method was used to adjust the survival analysis for African-American race and treatment group. To examine the association between genotype and extreme spontaneous preterm delivery, odds ratios and exact $95 \%$ confidence intervals were calculated for rates of spontaneous preterm delivery at less than 28 weeks of gestation. These odds ratios were adjusted for AfricanAmerican race and treatment group using logistic regression. Because we analyzed only three SNPs in candidate genes in this exploratory analysis, no adjustment was made for multiple comparisons. ${ }^{27}$

\section{RESULTS}

A total of 852 women were randomized in the trial of omega-3 supplementation for the prevention of recurrent preterm birth among women receiving 17-a-hydroxyprogesterone caproate. DNA samples were available for 834 women and satisfactory genotyping results were available for analysis for TNF-a-308 for 830 women (97.4\%), IL-6 -174 for 834 women (97.9\%), and IL-1 $\beta+3954$ for 833 women (97.8\%). Baseline characteristics of the 834 women are shown in Table 1 . The rate of spontaneous and indicated preterm delivery at less than 37 weeks of gestation was $34.2 \%$ and $5.5 \%$, respectively, and $60.3 \%$ delivered at term.

The frequencies of the minor alleles and homozygous minor genotypes for the three SNPs are shown in Table 2. The allele frequencies for all three SNPs observed Hardy-Weinberg equilibrium (TNF- $\mathrm{a}-308, P=.9$; IL-6 -174, $P=.10$; IL-1 $\beta+3954, P=.25$ ). The Kaplan-Meier curves comparing women with the homozygous minor genotype and those with either the heterozygous genotype or the homozygous major genotype are shown in Figures 1, 2, and 3.

Table 3 shows the median gestational ages at delivery with interquartile ranges by genotype, Cox proportional hazard ratios (risk of giving birth earlier adjusted for African-American race and treatment group), and the proportion with spontaneous preterm delivery before 28 weeks, with unadjusted and adjusted odds ratios (adjusted for African-American race and treatment group) and exact 95\% confidence interval. The TNF-a AA genotype was associated with shorter length of gestation (hazard ratio 1.74, 95\% confidence interval 1.04$2.90, P=.03$ ). Risk of spontaneous extreme preterm delivery (before 28 weeks of gestation) was increased in this group, with an adjusted odds ratio of 7.51 (95\% confidence interval 
1.84-30.72, $P=.005)$. There was no difference in length of gestation or risk of extreme preterm delivery by genotype for the IL-1 $\beta$ or IL-6 SNP (Table 3 ). We did not observe an association between clinical or histological chorioamniotis and genotypes for any of the three SNPs. Among the 15 women with the TNF-a -308 AA genotype, seven (or 46.7\%) delivered spontaneously at less than 37 weeks of gestation. Six of these experienced spontaneous preterm labor with delivery and one had preterm premature rupture of the membranes followed by preterm labor. The median gestational age at delivery for these seven was 34 weeks (interquartile range 24-35 weeks). The rate of the AA genotype was $1.8 \%$ for the cohort, $2.3 \%$ among white non-Hispanics, and 1.8\% among African-American non-Hispanics. There were no Hispanic women with this genotype.

\section{DISCUSSION}

The concept that genetic differences can modify the transcription of cytokines in response to an inflammatory stimulus has led investigators to explore the association between selected SNPs in candidate cytokine genes and rates of preterm delivery. In this cohort of women with at least one previous spontaneous preterm delivery, a homozygous genotype for guanine>adenine substitution at the -308 position in the promoter region of the TNF-a gene was associated with a significantly shorter length of gestation. Carriage of this allele is known to result in increased production of TNF- $\alpha$ and an altered inflammatory response is believed to increase the risk of extreme preterm birth. ${ }^{28-31}$ The association we observed between this genotype and spontaneous extreme preterm birth at less than 28 weeks of gestation therefore is intriguing. Because of the infrequency of this genotype and the outcome of extreme preterm birth, the number of observations available for assessing this association was small. We are not aware of any other studies that have examined this association.

Our results are consistent with the review by Crider et $\mathrm{al}^{32}$ who concluded the most consistent increase in preterm birth has been reported in studies of polymorphisms in the gene coding for TNF-a. IL-1 and IL-6 are also cytokines involved in pregnancy and increased levels in maternal and fetal fluids or tissues are associated with preterm birth; however, most studies have failed to find an association between spontaneous preterm delivery and polymorphisms in the genes coding for these cytokines. ${ }^{32} \mathrm{IL}-1 \beta+3954$ polymorphism is associated with increased protein production. ${ }^{33}$ Interestingly, the IL-6 -174 CC genotype is associated with decreased production of IL- $6 .{ }^{34} \mathrm{We}$ observed a nonsignificant reduction in the rate of spontaneous preterm delivery at less than 28 weeks of gestation among women with this genotype.

Not all studies have reported a significant association between maternal genotype for TNF- $\alpha$ -308 and preterm birth. ${ }^{19,} 35$ Differences in study results may be attributable to study design, sufficient power, or method of analysis. We used a cohort rather than a case-control study design. We assessed the associations between genotype and length of gestation rather than the outcome of preterm birth at less than 37 weeks of gestation. Also, most other studies have combined heterozygous (TNF-a -308GA) individuals with those homozygous (TNF-a-308AA) for the minor allele because of small numbers of homozygous AA individuals.

There are several strengths of this study. The conduct of the clinical trial provided opportunity for this prospective ancillary study in a well-characterized cohort with a high rate of preterm delivery. Gestational dating was set by uniform criteria that incorporated ultrasound assessment before 22 weeks of gestation. This is one of the largest cohorts of pregnant women genotyped for the TNF- $a-308$ SNP reported to date. Few studies have included more women with the homozygous minor genotype. A case-control study from 
Nashville included 534 women with TNF-a -308 genotyping and only nine with the AA genotype. This series was published with a meta-analysis of five previous studies, all with sample size smaller than ours, and the homozygous minor genotype was not analyzed separately. ${ }^{36}$ One larger cohort from Austria included 1,652 women, with 41 with the AA genotype; this group was at much lower risk, and hence the preterm birth rate was lower. ${ }^{37}$ We used Kaplan-Meier survival curves to assess the association between genotype and length of gestation. This may be a more appropriate model for assessing the genetic contribution to the complex trait of timing of parturition rather than the dichotomous outcome of term compared with preterm delivery. Although the cohort was at high risk, the TNF-a-308G $>$ A allele and genotype frequencies for the cohort as a whole and by race were similar to previously published frequencies, and all three SNPs were in HardyWeinberg equilibrium. ${ }^{36,37}$

The limitations of this study must be considered in interpreting the results. All women received 17-a-hydroxyprogesterone caproate because of their previous pregnancy histories. It is not known what effect, if any, 17-a-hydroxyprogesterone caproate may have on gene transcription or the inflammatory response. The number of women with the TNF- $\mathbf{a}-308$ AA genotype was small. We did not analyze fetal DNA. The relative contribution of the maternal and fetal genotypes to preterm birth has not yet been determined. Vaginal Gram stains were not available to correlate with genotypes and outcomes.

In conclusion, our results suggest polymorphism at the -308 position of the TNF- $\alpha$ promoter region which modulates gene transcription is associated with shorter gestation among women with at least one previous spontaneous preterm delivery. In addition, women with this genotype were at significantly increased risk for spontaneous extreme preterm delivery. Our findings support the concept that an altered inflammatory response predisposes to shorter gestation and extreme preterm birth.

\section{Acknowledgments}

Supported by grants from the Eunice Kennedy Shriver National Institute of Child Health and Human Development (NICHD) (HD27860, HD27917, HD40560, HD34208, HD40485, HD21410, HD27915, HD40500, HD40512, HD40544, MO1-relative risk-000080, HD34136, HD27869, HD40545, HD36801, HD19897). The views in this article do not necessarily represent the official views of the NICHD or the National Institutes of Health.

The authors thank Catherine Y. Spong, MD, for oversight, protocol development, and manuscript preparation; Paul J. Meis, MD, for protocol development; Julia Zachary and Yuan Zhao, MS, for protocol and data management and statistical analysis; and Karen Dorman, RN, MS, and Melissa Swain, RN, for coordination between clinical research centers.

\section{REFERENCES}

1. Preterm birth: crisis and opportunity. Lancet. 2006; 369:339.

2. Romero R, Espinoza J, Kusanovic JP, Gotsch F, Hassan S, Erez O, et al. The preterm parturition syndrome. BJOG. 2006; 113(Suppl 3):17-42. [PubMed: 17206962]

3. Dudley DJ. Pre-term labor: an intra-uterine inflammatory response syndrome? J Reprod Immunol. 1997; 36:93-109. [PubMed: 9430741]

4. So T, Ito A, Sato T, Mori Y, Hirakawa S. Tumor necrosis factor-alpha stimulates the biosynthesis of matrix metalloproteinases and plasminogen activator in cultured human chorionic cells. Biol Reprod. 1992; 46:722-728.

5. Arechavaleta-Velasco F, Ogando D, Parry S, Vadillo-Ortega F. Production of matrix metalloproteinase-9 in lipopolysaccharide-stimultated human amnion occurs through autocrine and paracrine proinflammatory cytokine-dependent systems. Biol Reprod. 2002; 67:1952-1958.

[PubMed: 12444074] 
6. Friebe-Hoffmann U, Chiao JP, Rauk PN. Effect of IL-1beta and IL-6 on oxytocin secretion in human uterine smooth muscle cells. Am J Reprod Immunol. 2001; 46:226-231. [PubMed: 11554696]

7. Rauk PN, Friebe-Hoffmann U, Winebrenner LD, Chiao JP. Interleukin-6 up-regulates the oxytocin receptor in cultured uterine smooth muscle cells. Am J Reprod Immunol. 2001; 45:148-153. [PubMed: 11270639]

8. Sadowsky DW, Novy MJ, Witkin SS, Gravett MG. Dexamethasone or interleukin-10 blocks inerleukin-1beta-induced uterine contractions in pregnant rhesus monkeys. Am J Obstet Gynecol. 2003; 188:252-263. [PubMed: 12548226]

9. Romero R, Espinoza J, Gonçalves LF, Kusanovic JP, Friel LA, Nien JK. Inflammation in preterm and term labour and delivery. Semin Fetal Neonatal Med. 2006; 11:317-326. [PubMed: 16839830]

10. Goepfert AR, Goldenberg RL, Andrews WW, Hauth JC, Mercer B, Iams J, et al. The Preterm Prediction Study: association between cervical interleukin 6 concentration and spontaneous preterm birth. National Institute of Child Health and Human Development Maternal-Fetal Medicine Units Network. Am J Obstet Gynecol. 2001; 184:483-488. [PubMed: 11228507]

11. Maymon E, Ghezzi F, Edwin SS, Mazor M, Yoon BH, Gomez R, et al. The tumor necrosis factor alpha and its soluble receptor profile in term and preterm parturition. Am J Obstet Gynecol. 1999; 181:1142-1148. [PubMed: 10561634]

12. Steinborn A, Günes H, Röddiger S, Halberstadt E. Elevated placental cytokine release, a process associated with preterm labor in the absence of intrauterine infection. Obstet Gynecol. 1996; 88:534-539. [PubMed: 8841213]

13. Winkler M, Kemp B, Fischer DC, Maul H, Hlubek M, Rath W. Tissue concentrations of cytokines in the lower uterine segment during preterm parturition. J Perinat Med. 2001; 29:519-527. [PubMed: 11776683]

14. Hillier SL, Witkin SS, Krohn MA, Watts DH, Kiviat NB, Eschenbach DA. The relationship of amniotic fluid cytokines and preterm delivery, amniotic fluid infection, histologic chorioamnionitis, and chorioamnion infection. Obstet Gynecol. 1993; 81:941-948. [PubMed: 8497360]

15. Porter TF, Fraser AM, Hunter CY, Ward RH, Varner MW. The risk of preterm birth across generations. Obstet Gynecol. 1997; 90:63-67. [PubMed: 9207815]

16. Mercer BM, Goldenberg RL, Moawad AH, Meis PJ, Iams JD, Das AF, et al. The preterm prediction study: effect of gestational age and cause of preterm birth on subsequent obstetric outcome. National Institute of Child Health and Human Development Maternal-Fetal Medicine Units Network. Am J Obstet Gynecol. 1999; 181:1216-1221. [PubMed: 10561648]

17. Bloom SL, Yost NP, McIntire DD, Leveno KJ. Recurrence of preterm birth in singleton and twin pregnancies. Obstet Gynecol. 2001; 98:379-385. [PubMed: 11530116]

18. Bhattacharya S, Raja EA, Mirazo ER, Campbell DM, Lee AJ, Norman JE, et al. Inherited predisposition to spontaneous preterm delivery. Obstet Gynecol. 2010; 115:1125-1133. [PubMed: 20502281]

19. Roberts AK, Monzon-Bordonaba F, Van Deerlin PG, Holder J, Macones GA, Morgan MA, et al. Association of polymorphism within the promoter of the tumor necrosis factor alpha gene with increased risk of preterm premature rupture of the fetal membranes. Am J Obstet Gynecol. 1999; 180:1297-1302. [PubMed: 10329893]

20. Simhan HN, Krohn MA, Zeevi A, Daftary A, Harger G, Caritis SN. Tumor necrosis factor-alpha promoter gene polymorphism -308 and chorioamnionitis. Obstet Gynecol. 2003; 102:162-166. [PubMed: 12850624]

21. Reiman M, Kujari H, Ekholm E, Lapinleimu H, Lehtonen L, Haataja L, et al. Interleukin-6 polymorphism is associated with chorioamnionitis and neonatal infections in preterm infants. $\mathrm{J}$ Pediatr. 2008; 153:19-24. [PubMed: 18571528]

22. Moore S, Ide M, Randhawa M, Walker JJ, Reid JG, Simpson NA. An investigation into the association among preterm birth, cytokine gene polymorphisms and periodontal disease. BJOG. 2004; 111:125-132. [PubMed: 14723749]

23. Genç MR, Gerber S, Nesin M, Witkin SS. Polymorphism in the interleukin-1 gene complex and spontaneous preterm delivery. Am J Obstet Gynecol. 2002; 187:157-163. [PubMed: 12114904] 
24. Speer EM, Gentile DA, Zeevi A, Pillage G, Huo D, Skoner DP. Role of single nucleotide polymorphisms of cytokine genes in spontaneous preterm delivery. Hum Immunol. 2006; 67:915923. [PubMed: 17145371]

25. Harper M, Thom E, Klebanoff MA, Thorp J Jr, Sorokin Y, Varner MW, et al. Omega-3 fatty acid supplementation to prevent recurrent preterm birth: a randomized controlled trial. Obstet Gynecol. 2010; 115:234-242. [PubMed: 20093894]

26. Dombrowski MP, Schatz M, Wise R, Momirova V, Landon M, Mabie W, et al. Asthma during pregnancy. Obstet Gynecol. 2004; 103:5-12. [PubMed: 14704237]

27. Attia J, Ioannidis JP, Thakkinstian A, McEvoy M, Scott RJ, Minelli C, et al. How to use an article about genetic association: B: Are the results of the study valid? JAMA. 2009; 301:191-197. [PubMed: 19141767]

28. Jeong P, Kim EJ, Kim EG, Byun SS, Kim CS, Kim WJ. Association of bladder tumors and GA genotype of -308 nucleotide in tumor necrosis factor-alpha promoter with greater tumor necrosis factor-alpha expression. Urology. 2004; 64:1052-1056. [PubMed: 15533517]

29. González S, Rodrigo L, Martínez-Borra J, López-Vázquez A, Fuentes D, Niño P, et al. TNF-alpha $-308 \mathrm{~A}$ promoter polymorphism is associated with enhanced TNF-alpha production and inflammation activity in Crohn's patients with fistulizing disease. Am J Gastroenterol. 2003; 98:1101-1106. [PubMed: 12809834]

30. Andrews WW. Cervicovaginal cytokines, vaginal infection, and preterm birth. Am J Obstet Gynecol. 2004; 190:1179. [PubMed: 15167814]

31. Goldenberg RL, Hauth JC, Andrews WW. Intrauterine infection and preterm delivery. N Engl J Med. 2000; 342:1500-1507. [PubMed: 10816189]

32. Crider KS, Whitehead N, Buus RM. Genetic variation associated with preterm birth: a HuGE review. Genet Med. 2005; 7:593-604. [PubMed: 16301860]

33. van Deventer SJ. Cytokine and cytokine receptor polymorphisms in infectious disease. Intensive Care Med. 2000; 26:S98-S102. [PubMed: 10786965]

34. Fishman D, Faulds G, Jeffery R, Mohamed-Ali V, Yudkin JS, Humphries S, et al. The effect of novel polymorphisms in the interleukin-6 (IL-6) gene on IL-6 transcription and plasma IL-6 levels, and an association with systemic-onset juvenile chronic arthritis. J Clin Invest. 1998; 102:13691676. [PubMed: 9769329]

35. Dizon-Townson DS, Major H, Varner M, Ward K. A promoter mutation that increases transcription of the tumor necrosis factor-alpha gene is not associated with preterm delivery. Am J Obstet Gynecol. 1997; 177:810-813. [PubMed: 9369824]

36. Menon R, Merialdi M, Betrán AP, Dolan S, Jiang L, Fortunato SJ, Williams S. Analysis of association between maternal tumor necrosis factor-alpha promoter polymorphism (-308), tumor necrosis factor concentration, and preterm birth. Am J Obstet Gynecol. 2006; 195:1240-1248. [PubMed: 17074545]

37. Stonek F, Bentz EK, Hafner E, Metzenbauer M, Philipp K, Hefler LA, Tempfer CB. A tumor necrosis factor-alpha promoter polymorphism and pregnancy complications: results of a prospective cohort study in 1652 pregnant women. Reprod Sci. 2007; 14:425-729. [PubMed: 17913961] 


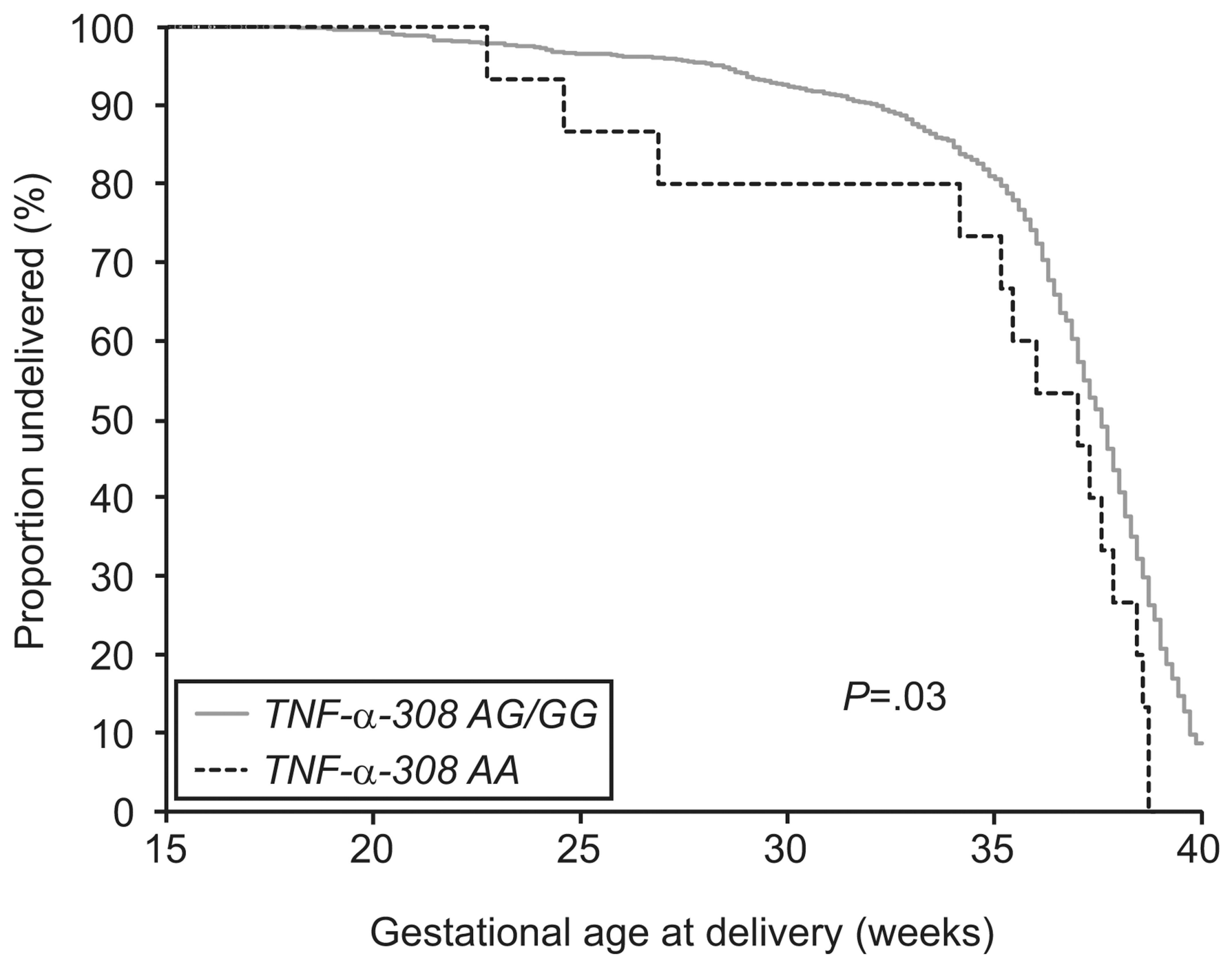

Fig. 1.

Kaplan-Meier curve. Length of gestation censored at 40 weeks of gestation by tumor necrosis factor (TNF)-a -308 genotype. TNF-a -308 AG/GG represents women heterozygous and homozygous for the usual allele. TNF- $\mathbf{a}-308$ AA represents women homozygous for the minor allele.

Harper. Inflammatory Cytokine Gene Polymorphisms. Obstet Gynecol 2011. 


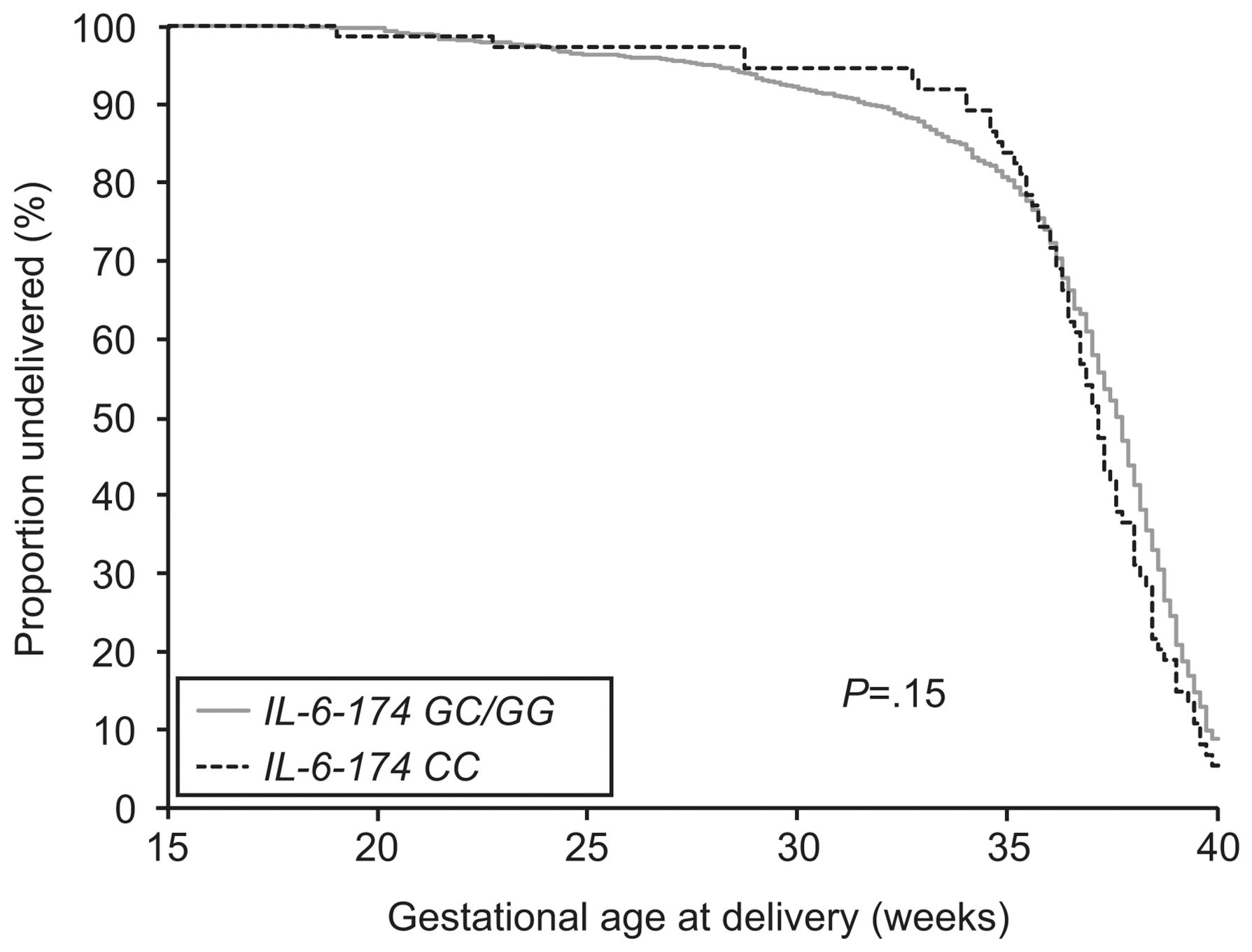

Fig. 2.

Kaplan-Meier curve. Length of gestation censored at 40 weeks by interleukin (IL)-6-174 genotype. IL-6-174 GC/GG represents women heterozygous and homozygous for the usual allele. IL-6-174 CC represents women homozygous for the minor allele.

Harper. Inflammatory Cytokine Gene Polymorphisms. Obstet Gynecol 2011. 


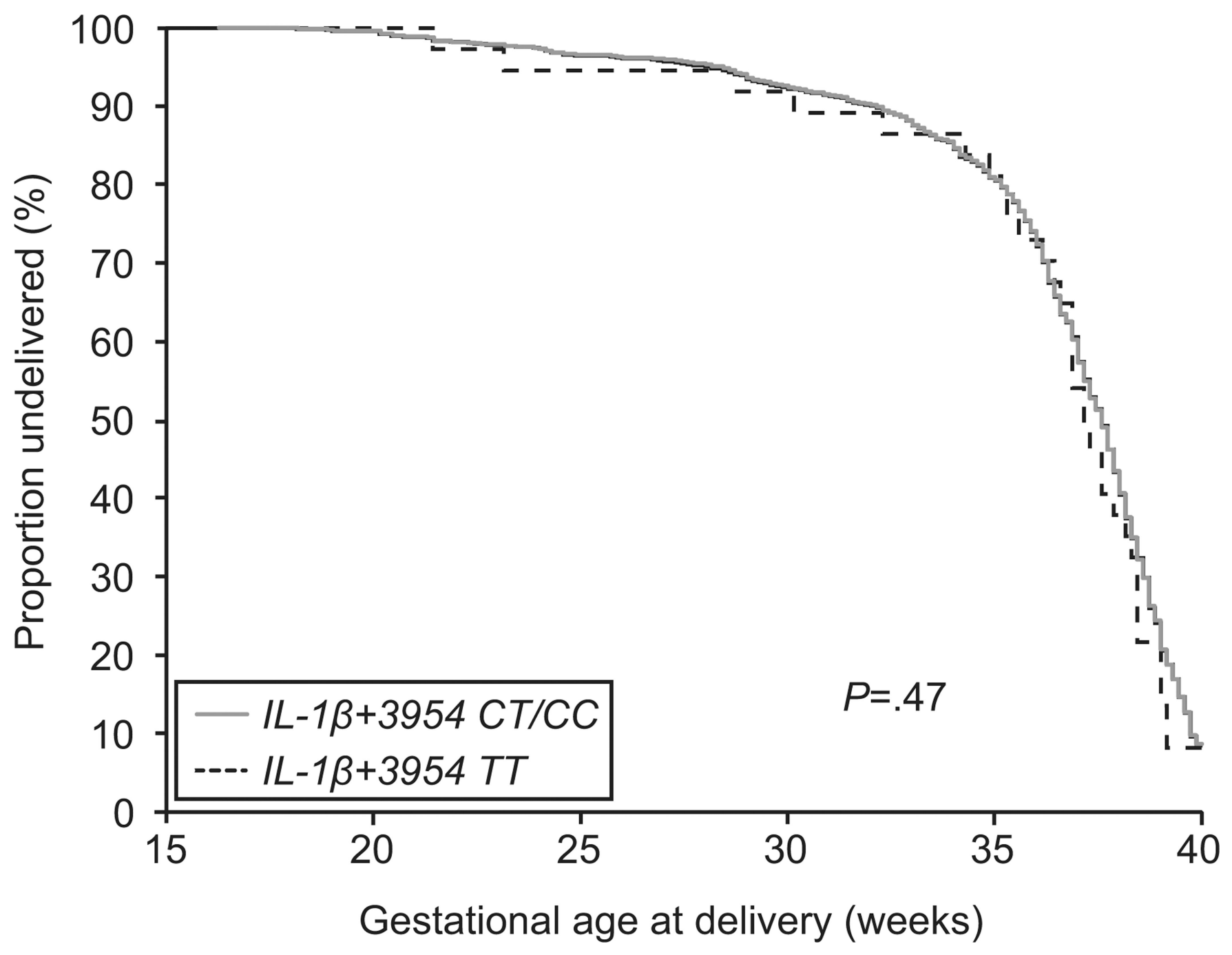

Fig. 3.

Kaplan-Meier curve. Length of gestation censored at 40 weeks of gestation by interleukin (IL)-1 $\beta+3954$ genotype. IL-1 $\beta+3954 \mathrm{CT} / \mathrm{CC}$ represents women heterozygous and homozygous for the usual allele. IL-1 $\beta+3954$ TT represents women homozygous for the minor allele.

Harper. Inflammatory Cytokine Gene Polymorphisms. Obstet Gynecol 2011. 
Table 1

Characteristics of the Cohort With DNA Analysis

\begin{tabular}{lc}
\hline Age (y) & $\mathbf{2 7}(\mathbf{2 3 - 3 2 )}$ \\
Racial distribution & 34.7 \\
African American & 56.5 \\
White & 2.2 \\
Asian & 6.7 \\
Other & \\
Ethnicity & 14.2 \\
Hispanic & 85.8 \\
Non-Hispanic & 29.4 \\
Proportion with 2 or more previous preterm deliveries & $32(26-34)$ \\
Gestational age of earliest previous spontaneous preterm delivery (wk) & $19(18-20)$ \\
Gestational age at randomization (wk)
\end{tabular}

Data are median (interquartile range) or $\%$. 
Table 2

Minor Allele and Homozygous Minor Genotype Frequencies

\begin{tabular}{lccc}
\hline & $\begin{array}{c}\text { TNF-a } \\
\mathbf{- 3 0 8}\end{array}$ & $\begin{array}{c}\text { IL-6 } \\
\mathbf{- 1 7 4}\end{array}$ & $\begin{array}{c}\text { IL-1 } \\
\mathbf{+ 3 9 5 4}\end{array}$ \\
\hline Frequency of the minor allele & $13.9 \%$ & $27.5 \%$ & $19.0 \%$ \\
Patients homozygous for the minor allele & $15(1.8)$ & $74(8.9)$ & $37(4.4)$ \\
\hline
\end{tabular}

TNF, tumor necrosis factor; IL, interleukin.

Data are $\%$ or n $(\%)$. 


$$
\begin{aligned}
& \text { 茓 } \\
& \text { ล }
\end{aligned}
$$

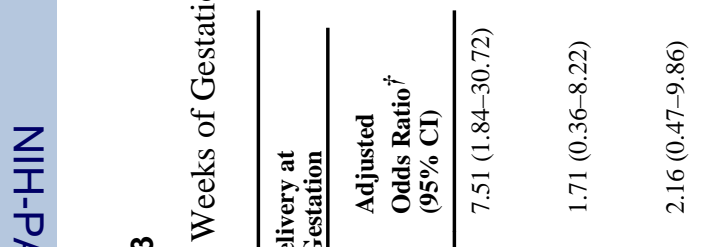

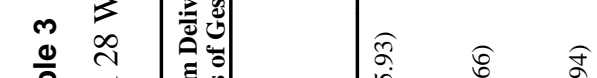

$$
\begin{aligned}
& \text { 站 } \stackrel{\frac{0}{\circ}}{\frac{1}{\sigma}}
\end{aligned}
$$

